\title{
SIPUT PROSOBRANCHIA (GASTROPODA, MOLUSKA) PADA RATAAN TERUMBU KARANG DI TELUK MANADO
}

\author{
(Prosobranchia snails (Gastropods, Molluscs) at the coral reef flat \\ in Manado Bay)
}

\author{
Jevvrandi E. Bambulu*, Farnis B. Boneka, Billy Th. Wagey \\ Program Studi IImu Kelautan Fakultas Perikanan dan IImu Kelautan \\ Universitas Sam Ratulangi, Manado. \\ *e-mail: jevvrandiBambulu@gmail.com
}

\begin{abstract}
Molluscs are marine organisms that do not have a backbone, these organisms are associated with coral reefs. This research was conducted with the aim of describing the density and diversity of Prosobranchia snails' species on coral reef flats. By applying the belt transect method, the results show that the density of the four Mokupa stations has a relatively high density between Tongkeina, Malalayang and Bulo. While for species diversity, Mokupa and Bulo had the highest value than Tongkeina and Malalayang. According to the results of the belt transect method, is the concluded that stations close to people's homes have the lowest density and species diversity values, this factor is influenced by anthropogenic activities or human activities. Therefore, it is recommended that there be monitoring of snails on coral reefs, especially reef flattening in order to provide information about Prosobranchia snails.
\end{abstract}

Keywords: Prosobranchia, Density, diversity, belt transects, Reef Flats

Moluska merupakan organisme laut yang tidak memiliki tulang belakang. Organisme ini berasosiasi dengan terumbu karang. Penelitian ini dilakukan dengan tujuan untuk mendeskripsikan kepadatan dan keanekaragaman spesies, siput Prosobranchia pada rataan terumbu karang. Dengan menerapkan metode belt transek, diperoleh hasil bahwa kepadatan dari empat stasiun mokupa memiliki kepadatan yang relatif tinggi diantara Tongkeina, Malalayang dan Bulo. Sedangkan untuk keanekaragaman spesies, Mokupa dan Bulo nilainya paling tinggi dari Tongkeina dan Malalayang. Sesuai dengan hasil metode belt transek menyimpulkan stasiun yang berdekatan dengan rumah warga memiliki nilai kepadatan dan keanekaragaman spesies paling rendah, faktor ini dipengaruhi kegiatan antropogenik atau aktifitas manusia. Untuk itu disarankan adanya monitoring tentang siput di terumbu karang khususnya di rataan terumbu agar bisa memberikan informasi tentang siput Prosobranchia.

Kata kunci : Prosobranchia, Kepadatan, keanekargamn, belt transek, rataan terumbu 


\section{PENDAHULUAN}

Keanekaragaman hayati pesisir dan lautan Indonesia hadir dalam bentuk ekosistem terumbu karang, ekosistem mangrove ekosistem padang lamun, ekosistem estuari, ekosistem laut terbuka. Berbagai ekosistem tersebut saling berhubungan secara sinergis melalui aliran arus air dan migrasi biota (Dahuri, 2003). Di beberapa ekosistem tersebut tersimpan sumberdaya yang cukup potensial antara lain moluska dengan keanekaragaman spesies yang tinggi (Dharma 2005).

Moluska tergolong biota yang memiliki keanekaragaman spesies yang tinggi dan menyebar luas di berbagai habitat laut.Mulai dari zona supratidal hingga laut dalam, habitat moluska adalah substrat yang berbatubatu termasuk karang batu, batu cadas serta pecahan karang di daerah Intertidal dan Subtidal. Dharma (2005) menyatakan bahwa moluska banyak menempati daerah terumbu karang. Di antara group Filum Moluska Subklas Prosobranchia merupakan komponen biologi yang penting di terumbu karang. Sebagian jenis Siput Prosobranchia menjadi bahan makanan.

Penelitian tentang Siput Prosobranchia di wilayah Sulawesi Utara khususnya yang menempati daerah terumbu karang antara lain dilakukan oleh Boneka (1995), Dako (1996) dan oleh Parinsi (1997) untuk di daerah padang lamun atau rumput laut Studi tersebut diatas tergolong cukup lama, sehingga dipandang perlu untuk mendokumentasikan kembali Siput Prosbranchia di rataan terumbu karang.

\section{METODE PENELITIAN}

Teknik pengambilan sampel menggunakan metode Belt Transek atau yang biasa dikenal dengan metode transek sabuk digunakan untuk menggambarkan kondisi populasi suatu jenis biota yang akan diidentifikasi (English $d k k$, 1994). Tiga buah transek sepanjang 50 meter diletakan di rataan terumbu, ke arah laut tegak lurus dengan garis pantai. Jarak antara garis transek yang satu dengan yang lain kurang lebih 25 meter (Gambar 4).?

Sampling dilakukan pada siang hari pada saat air laut surut dengan melakukan snorkeling di sepanjang transek pada kedalaman 0-4 meter. Setiap siput yang masih hidup yang ada di sisi kiri dan kanan tali transek, dengan jarak 1 meter ke kiri dan 1 meter ke kanan,dipungut dan dimasukan ke dalam kantong plastik yg sudah di beri lebel. Sampel atau specimen diawetkan dengan alkohol $70 \%$ dan selanjutnya diidentifikasi hingga level spesies.

\section{Waktu dan Lokasi Penelitian}

Lokasi penelitian berada di wilayah Teluk Manado. Teluk Manado terbentang mulai dari Tanjung Pisok sampai Tanjung Mandolang. Tanjung Pisok berada di keluarahan Tongkeina sedangkan Tanjung Mandolang di wilayah pantai Desa Tateli. Lokasi sampling terdiri dari 4 Stasiun yaitu Tongkeina, Malalayang, Bulo dan Mokupa (Gambar 3).

Waktu pengumpulan data di lapangan pada bulan April sampai Juni 2020. Pengumpulan spesimen siput di rataan terumbu karang dilaksanakan pada saat air laut sedang surut. Hal ini untuk mempermudah pengambilan sampel. Sampel diidentifikasi hingga level spesies dan di foto. Data berupa jumlah individu pada setiap spesies siput ditabulasi. 


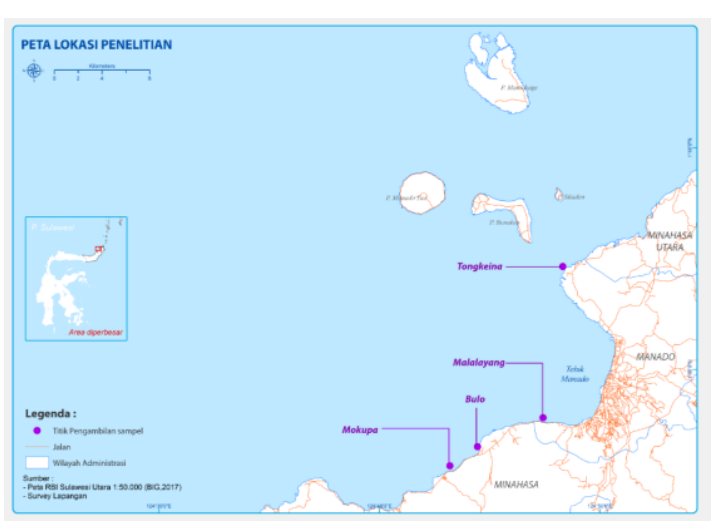

Gambar 3. Lokasi Penelitian

\section{Alat dan Bahan}

Alat dan bahan yang digunakan pada pengambilan sampel siput Prosobranchia Gastropoda di rataan terumbu karang di Pantai Teluk Manado.

Global Position System (GPS) untuk menentukan posisi koordinat stasiun penelitian.

a. Kamera Samsung J3 PRO diberi pelindung tahan air (housing) tahan terhadap rembesan air laut, untuk dokumentasi bawah air.

b. Meter roll untuk dan tali rafia sebagai garis transek

c. Kantong plastik untuk menampung spesimen atau sampel siput

d. Masker dan snorkel alat untuk membantu bernapas saat mengumpul sampel

e. Buku Panduan identifikasi Molluska, antara lain (Dharma, 2005).

f. Alat ukur (mistar sorong) untuk mengukur panjang cangkang siput

\section{Keadaan Umum Lokasi Penelitian}

Posisi geografis lokasi penelitian ditunjukkan pada Tabel 2 . Stasiun Tongkeina terletak di tanjung bagian utara teluk Manado; sedangkan lokasi Malalayang, Bulo dan Mokupa terletak di bagian dalam teluk Manado. Tabel 2. Posisi geografis lokasi penelitian.

\begin{tabular}{|l|c|l|}
\hline No & Stasiun & \multicolumn{1}{|c|}{ Titik Kordinat } \\
\hline 1 & Tongkeina & $\begin{array}{l}1^{\circ} 34^{\prime} 38,4^{\prime \prime} \text { LU } \\
1^{\circ} 44^{\circ} 48^{\prime} 18,8^{\prime \prime} \mathrm{BT}\end{array}$ \\
\hline 2 & Malalayang & $\begin{array}{l}1^{\circ} 27^{\prime} 48,8^{\prime \prime} \mathrm{LU} \\
1^{\circ} 44^{\circ} 47^{\prime} 25,3^{\prime \prime} \mathrm{BT}\end{array}$ \\
\hline 3 & Bulo & $\begin{array}{l}1^{\circ} 26^{\prime} 30,9^{\prime \prime} \mathrm{LU} \\
1^{\circ} 4^{\circ} 44^{\prime} 27,2^{\prime \prime} \mathrm{BT}\end{array}$ \\
\hline 4 & Mokupa & $\begin{array}{l}1^{\circ} 25^{\prime} 39,3^{\prime \prime} \mathrm{LU} \\
1^{\circ} 44^{\circ} 43^{\prime} 11,9^{\prime \prime} \mathrm{BT}\end{array}$ \\
\hline
\end{tabular}

\section{Analisis Data}

Kelimpahan organisme dapat disajikan dengan mengukur kepadatan (Krebs 1989). Kepadatan adalah besarnya populasi dalam suatu unit ruang yang dinyatakan dalam jumlah individu dari populasi dalam suatu unit (Odum 1971).

Kepadatan $=\frac{\text { Jumlah individu }}{\text { Luas areal }}$

Dalam penelitian ini, luas area adalah 50 meter panjang transek $X 2$ meter lebar $=100$ (ind/ha) Dengan demikian, jumlah individu siput yang diperoleh dalam setiap transek dibagi dengan $100 \mathrm{~m}^{2}$. Data yang ditampilkan dalam tabel merupakan nilai rata-rata dari 3 ulangan atau replikasi. (Elliot, 1983).

Keanekaragaman spesies dianalisa berdasarkan rumus (Krebs 1989 dan Odum 1971) yaitu :

$\mathrm{H}^{\prime}=-\sum_{i-1}^{n}\left(n_{i} / \mathrm{N} \ln n_{i} / \mathrm{N}\right)$

Dimana, $\mathrm{S}=$ Jumlah spesies

$$
\mathrm{n}_{i}=\underset{\text { jenis ke-i }}{\text { Jumlah individu dalam }}
$$

$\mathrm{N}=$ Jumlah individu total

Jika,

$H^{\prime}<1$ : Keanekaragaman rendah

$1<H^{\prime}<3$ : Keanekaragaman sedang

$\mathrm{H}^{\prime}>3$ : Keanekaragaman tinggi 
HASIL DAN PEMBAHASAN

\section{a, Kepadatan Siput Prosobranchia}

Kepadatan (ind./ha) menurut Transek di Tongkeina

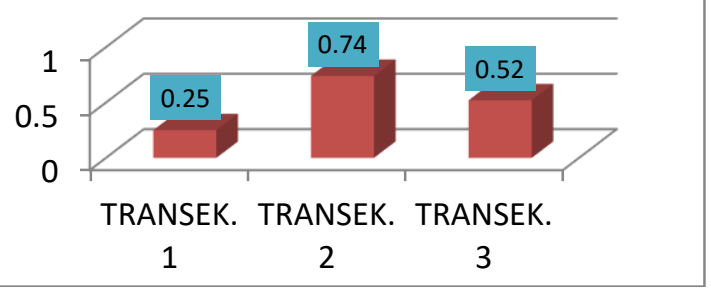

Kepadatan (ind./ha) menurut Transek di Malalayang

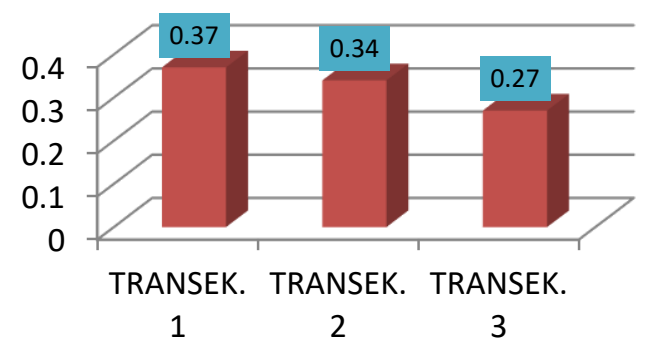

Kepadatan (ind/ha) menurut Transek di Mokupa

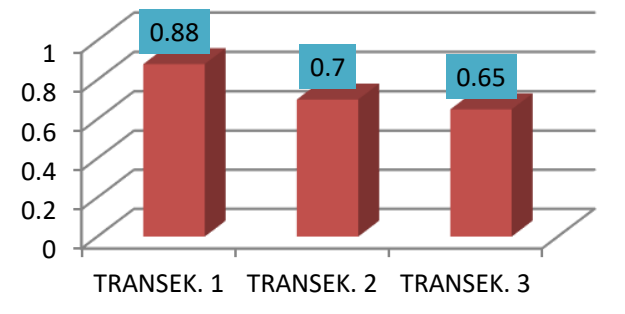

Kepadatan (ind./ha) menurut Transek di Bulo

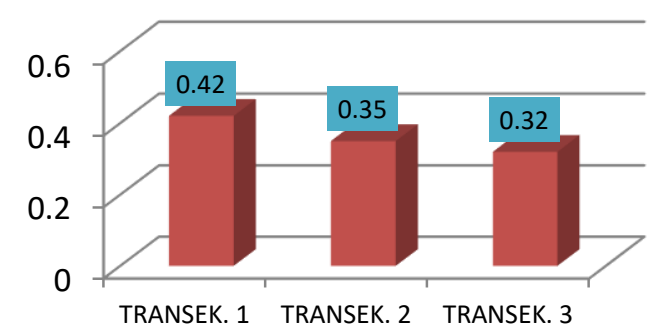

Kepadatan (ind/ha) siput menurut transek pada masing-masing lokasi.

Dari keempat stasiun penelitian ditemukan bedasarkan data yang ada bahwa hasil yang ditemukan di tabulasi menggunakan perangkat mikrosoft exel kemudian diaplikasikan dalam bentuk diagram dengan stasiun Mokupa memiliki tingkat kepadatan siput yang masuk dalam kategori sedang karena melihat jumlahnya 0.88 (ind/ha). Stasiun Tongkeina berada pada urutan kedua dengan jumlah kepadatan 0.74 (ind/ha) kemudian stasiun Bulo berada pada urutan ketiga dengan jumlah kepadatan 0.42 (ind/ha) dan yang terakhir Malalayang kepadatanya sangat sedikit hanya memiliki nilai 0.37 (ind/ha).

\section{b, Keanekaragaman Spesies}
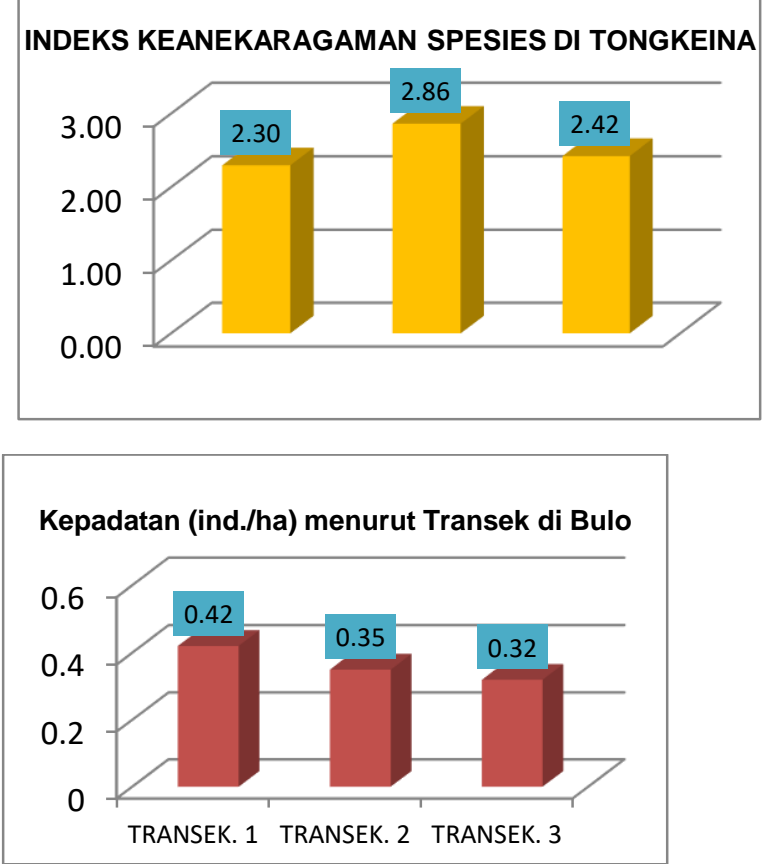

INDEKS KEANEKARAGAMAN SPESIES DI MALALAYANG

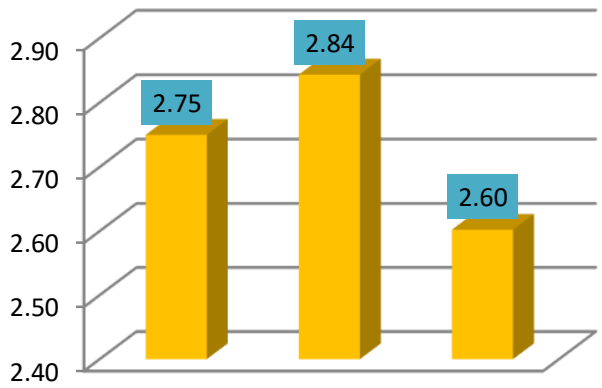



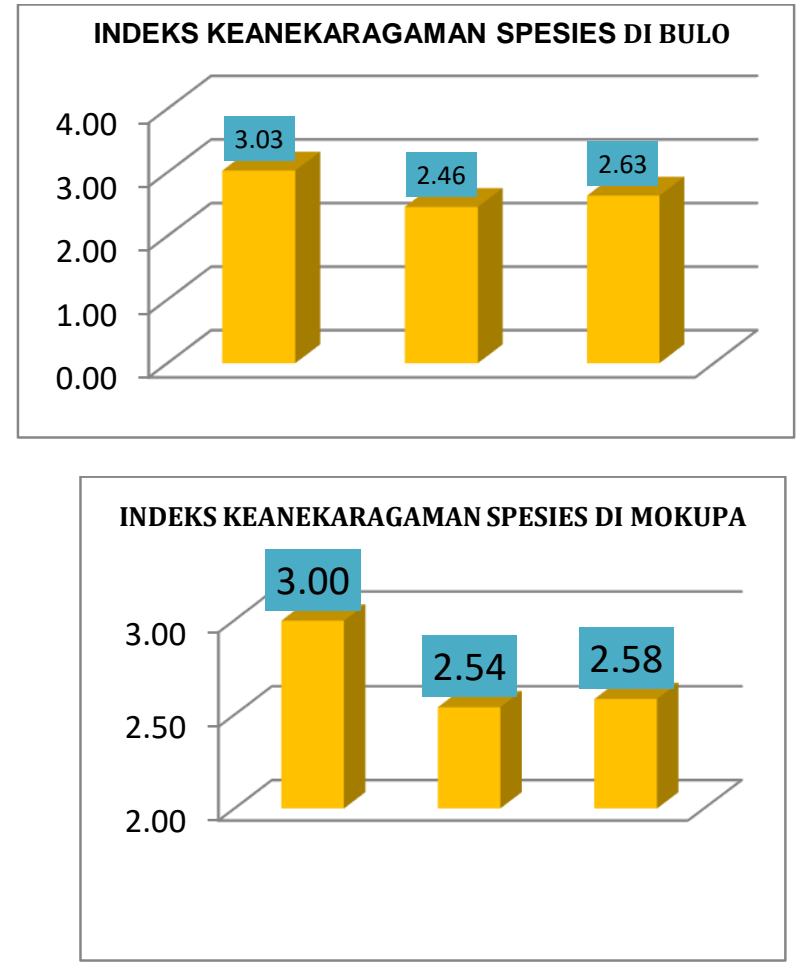

Indeks keanekaragaman spesies dari empat stasiun yang paling tinggi berada pada lokasi Bulo dengan nilai 3.03 disusul oleh stasiun Mokupa 3.00 sedangkan untuk stasiun Tongkeina dan Malalayang nilainya sangat bervariasi antara 2.84-2.86. Dengan ini dapat disimpulkan bahwa untuk indeks keanekaragaman spesies siput Prosobranchia dari keempat lokasi untuk stasiun Bulo dan Mokupa termasuk dalam kategori sedang. Sedangkan stasiun Tongkeina dan Malalayang berada dalam kategori kurang. Hal yang menjadi faktor penyebab perbedaan indeks keanekaragaman adalah aktifitas manusia, faktor alam dan juga kompetisi antar spesies.

\section{KESIMPULAN}

Berdasarkan penelitian yang dilakukan maka dapat di simpulkan,

1. Siput Prosobranchia yang diperoleh dari terumbu karang di Teluk Manado sebanyak 50 jenis dari 14 famili, dengan variasi jumlah spesies stasiun adalah 28-
40 spesies; dengan stasiun Mokupa paling banyak jumlah spesies.

2. Siput Prosobranchia yang umum di rataan terumbu karang Teluk Manado adalah Drupella cornus, Peristernia nassatula, Latirolagena smaragdula, Conus (Virroconus) ebraeus, Conus (Lividoconus) lividus, Conus (Virgiconus) virgo, Cypraea (Erosaria) moneta dan Angaria delphinus

3. Kepadatan siput Prosobranchia di terumbu karang Teluk Manado berada pada kisaran 32,7-74,3 individu/ha; dengan kepadatan tertinggi di Stasiun Mokupa dan terendah di Malalayang

4. Indeks keanekaragaman di empat stasiun yang paling tinggi berada pada lokasi Mokupa dan Bulo sedangkan Tongkeina dan Malalayang nilainya sangat Varian.

\section{DAFTAR PUSTAKA}

Arikunto, dan Suharsimi, 2006. Prosedur Penelitian Suatu Pendekatan Praktik Rineka Cipta Jakarta.

Antonius, A. \& Riegl B.1987. Penyakit Karang dan Invasi Drupella Cornus di Laut Merah" Terumbu Karang. 17 (1): 48.

Alf A. \& Kreipl K. 2003. Ikonografi Konkologis: Keluarga Turbinidae. Subfamili Turbinininae, Genus Turbo. Buku Conch, Hackenheim Jerman.

Anonymous, 2021. World Register of Marine Species (WoRMS) http://www.marinespecies.org/ aphia.php? $\mathrm{p}=$ taxdetails\&id $=13$ 8491 diakses pada 28 Januari 2021 
Boneka, F.B. 1995. Gastropoda di daerah Rataan Terumbu Karang Taman Nasional Bunaken. Laporan.Fak. Perikanan Universitas Sam Ratulangi. 14 hal

Bouchet, P. 2012a. Astrea Calcar, Diakses Melalui: Daftar Spesies Laut Dunia.

Bouchet, P. 2020b. Canarium Mutabile (Swainson, 1821) Diakses Melalui: Daftar Spesies Laut Dunia.

Barnes, R.D. 1974. Invertebrate zoology. WB. Sounders Company. Philadelphia London. Toronto. Hal 317 431

Bieler, R. \& PM Mikkelsen (eds.). 1992. Handbook of Systematic Malacology, Part 1 (Loricata [Polyplacophora]; Gastropoda: Prosobranchia) .

Dharma, B. 2005. Recent and Fosil Indonesian Shells. PT Mandiriabadi. Indonesia. Dibyowati, L. 2009. Keanekaragaman Moluska (Bivalvia).

Dahuri, R, J.Rais, S.P. 2003.

Keanekaragaman Hayati Laut:

Aset Pembangunan

Berkelanjutan Indonesia.

Gramedia Pustaka Utama.

Jakarta

Dako, R. 1996. Kekayaan dan Kelimpahan Gastropoda di Rataan Terumbu Karang Pantai Utara Minahasa.SKRIPSI.Fakultas Perikanan dan IImu Kelautan UNSRAT. Manado.

Elliot, J.M. 1983. Some Methods For the Statistical Analysis of Samples of Benthic Invertebrates. Fresh Water
Biological association. Sci. Publ. No. 25. 159 hal.

English S. Wilkinson C, Baker VJ. (editors) 1994. Survey Manual for Tropical Marine Resources.ASEAN

Australia.Marine Science Project. Australian Institute or Marine Science, Twonsville.

Esti, A.H. 2006. Keanekaragaman Jenis Gastropoda Di Pantai Randusanga Kabupaten Brebes Jawa Tengah. Skripsi. FMIPA Universitas Negeri Semarang. Semarang. Hal 8-9.

F. Welter Shulter, 2013 Indeks Animalium (Sherbrn. Spesies dan Genera Sampai Tahun 1850).

GBIF Secretariat 2019. GBIF Backbone Taxonomy. Ceklist Data Setahun.

Gmelin J.F. 1971. Vermes. Dalam: Gmelin JF (Ed.) Caroli a Linnaei Systema Naturae Oleh Regna Tria Naturae, Ed. 13 Besar 1 (6). GE Beer, Lipsiae [Leipzig]. HIm. 3021-3910.

Herbert G.G. 1993. Revisi Trochinae, Suku Trochini (Gastropoda: Trochinae) dari Afrika Bagian Selatan. Sejarah Museum Kelahiran 34 (2): 239-308.

Kronberg, G. C. 1988. Strombu (Canarium) cf. Ochroglottis.

Krebs, C.J. 1989. Ecological Methodology. Harper and Row. New York. 654 hal.

Kusnadi, dkk. 2008. kelas Gastropoda umumnya dikenal dengan keong atau Siput. hal 7.

Liverani V. 2014. Superfamili Strombidea. Tambahan dan Korrigenda. Dalam: GT Poppe, 
K. Groh \& C. Renker (eds), Sebuah Ikonografi hlm 1-54, Pls 131-164, Harxheim : Buku Conch.

Lilley, M. 1999. Buku Panduan Pendidikan Konservasi Terumbu Karang Indonesia.Natural Resources Management Program.56 hal.

Mudjiono. 2009. Telaah Komunitas Moluska di Rataan Terumbu (Reef Flat) Perairan Kepulauan Natuna Besar, Kabupaten Natuna, Oseonologi dan Limnologi di Indonesia, 35 (2) : 147-160.

Moluska Base eds. 2021. Moluska Base: Utensil Ceramicum (1758).

Mori K dan Tanaka M. 1989. Intertidal community structures and environmental condition of exposed and sheltered rocky shores in Amakusa. Publ Amakusa Mar. Biol. Lab. Japan. 863.25.

Nontji, A. 2002. Laut Nusantara. Djambatan. Jakarta. Hal : 161 $-173$

Odum E.P. 1971. Fundamental of Ecology. W. B. Sounder Company London.

Ofri. 2009. Studi Awal tentang populasi dan dampak predator gastropoda Drupella sp. Terhadap kematian karang.Departemen

Manajemen Sumberdaya Perairan Fakultas Perikanan dan Ilmu Kelautan Institut Petanian Bogor.

Parinsi A. E. 1997. Komunitas prosobranchia (Mollusca Gastropoda) di daerah rumput laut pantai utara Minahasa.
Skripsi FPIK UNSRAT. Manado. 46 hal.

Poppe G.T. \& Tagaro S.P. 2008. Mitridae. Pp. 330-417, Dalam: GT Poppe (ed,), Moluska Laut Filipina, Vol.2. Hackenheim: ConchBook.

Rusyana, Adun. 2011. Zoologi Invertebrata.Bandung Alfabeta

Rosenberg, G. 2014. Trochus Tubiferus Kiener, 1850. Diakses Melalui: Daftar Spesies Laut Dunia.

Riska, Baru Sadarum, La Ode Muh Yasir Haya, 2013. Jurnal Mina Laut Indonesia.Kelimpahan Drupella dan kondisi terumbu karang di perairan Mandike Selat Tiworo kabupaten Muna, Sulawesi Tenggara.Program studi manajemen sumberdaya perairan FPIK.Universitas Haluoleo kampus hijau bumi Tridarma.Kendari 93232.

Suharsono, 1996. Jenis jenis Karang yang umum dijumpai di Indonesia. Lembaga Pengetahuan Indonesia. Jakarta. 116 hal.

Saroinsong. A.E. 1998. Komunitas Gastropoda di zona Intertidal substrat lunak Teluk Manado.Skripsi.Fakultas Perikanan dan IImu Kelautan UNSRAT Manado.46 hal.

Takada Y. dan Kikuchi T. 1990. Mobile moluscan communities in Boulder shores and the comparison with other intertidal habitats in Amakusa. Publ. Amakusa Mar. Biol. Lab. Japan. 864.25.

Tsuchia, K. 2000. Famili Muricidae. In; Okutani, T. (ed.), Marine Molusks. 
Williams ST. Karube S. \& Ozawa T. 2008. Sistematika Molekuler Vetigastropoda : Trochidae, Turbinidae, dan Trochidea Didefinisikan Ulang. Zoologica Scripta 37 : 483-506.

Worms. 2009. Monetaria Annulus (Linnaeus). Diakses Melalui Daftar Spesies Laut Dunia. 